\title{
Comparison of tendency and accuracy in predicted post-operative refraction and recommended IOL power between IOL Master and VERION before and after optimizing IOL-constant in the VERION
}

Takeshi Teshigawara ( $\nabla$ teshitake@gmail.com )

Yokosuka Chuoch Eeye Clinic https://orcid.org/0000-0001-8264-101X

Akira Meguro

Department of Ophthalmology, Yokohama City University School of Medicine

Nobuhisa Mizuki

Western University Department of Ophthalmology

Research article

Keywords: Cataract surgery, Intraocular lenses, IOL constant optimization, IOL power calculation accuracy, VERION, IOL Master 700, Biometry

Posted Date: January 20th, 2020

DOl: https://doi.org/10.21203/rs.2.21267/v1

License: (c) (1) This work is licensed under a Creative Commons Attribution 4.0 International License.

Read Full License 


\section{Abstract}

Background: We assessed the accuracy and tendency of the VERION image-guided system (Alcon) and the intra-ocular lens (IOL) Master 700 (Zeiss), by comparing mean refractive shift (MRS) of predicted post-operative refraction (PPR), mean absolute error (MAE) of PPR, recommended IOL power (RIP) and Kvalue before and after optimizing the IOL-constant in VERION, to show the importance of optimization.

Methods: This retrospective study involved 72 eyes. K-value was measured with both biometers. Axial length (AL) and anterior chamber depth (ACD) measured by the IOL Master were applied to the VERION because it cannot measure these variables. The User group for Laser Interference Biometry (ULIB) IOLconstant for the IOL Master was applied to the VERION before optimizing the IOL constant, since no such official measure was established for it. MRS of PPR, MAE of PPR, RIP and K-value as measured by both biometers were compared before and after optimizing the IOL-constant in the VERION. Finally, correlations between the MRS, MAE, RIP, and K-value were analyzed in the VERION. The Wilcoxon signedrank test was used for analysis.

Results: Compared to the IOL Master, K-value was significantly higher in the VERION. Prior to optimization, MRS of PPR showed a significant myopic shift in the VERION, and MAE of PPR was significantly higher. Additionally, RIP in the VERION was significantly lower. After optimization, there were no significant differences in the MRS of PPR and RIP between the VERION and IOL Master. MAE of PPR in the IOL Master was significantly higher than in the VERION. No significant correlations were found between MRS and MAE of PPR and RIP with K-value in the VERION.

Conclusions: Before optimization, the VERION was less reliable in MRS, MAE and RIP than the IOL Master. However, after optimization, the difference in MRS and RIP between the two devices became insignificant. This study indicates that optimization of IOL-constant in the VERION is vital. After optimization, the VERION is more accurate in PPR than the IOL Master.

\section{Introduction}

A good refractive outcome following cataract surgery, has been regarded as a vital part of refractive surgery following increased patients expectations. Therefore, more accurate prediction of post-operative refraction is required [1-3], as surgery aims for the independence of an individual from spectacle correction and improved quality of life [4]. It is thus understandable that the accuracy of these calculations is increasingly critical [5], as post-operative visual acuity has been associated with the accuracy of measurements, prior to cataract surgery [6]. Most intra-ocular lens (IOL) calculation formulas include K-value as one of several biometric variables [7-9]. Therefore, a precise measurement of K-value is crucial [10].

In general, the more peripheral the cornea, the flatter it is $[11,12]$. However, currently available optic biometers measure the curvature of the cornea at different points [13]. This indicates that the predicted 
post-operative refraction (PPR) and recommended IOL power (RIP), using current calculation formulas, could vary depending on which optic biometer was used to measure K-value.

The VERION image-guided system (Alcon, Fort Worth, TX, USA) is the latest system to improve the accuracy of post-operative vision correction, after cataract surgery [14]. It can be used both pre- and intraoperatively. The image taken pre-operatively can be applied for auto-registration using the intraoperative digital marker. The VERION Reference Unit measures K-value at a range of $0.8-1.2 \mathrm{~mm}$, from the apex of the cornea, which is more centered than other optic biometers, similar to the IOL Master 700 (Carl Zeiss Meditec AG, Jena, Germany). Theoretically speaking, as Holladay argued, K-values measured with the VERION can be slightly steeper than those measured with other devices, including the IOL Master 700 [13]. However, there is also research that has demonstrated that K-value in the VERION did not show a significant difference when compared to other optic biometers $[15,16]$. To add to the debate among studies, although previous research has indicated that several outcome measures with the VERION are yet to be fully evaluated [17], others support that it can be used interchangeably with the IOL Master when it comes to keratometry measurements [18]. At the same time, others suggest it cannot and that the superiority of one system over the other cannot be established [19].

The aims of the current study were to investigate the differences in K-value between the VERION and the IOL Master 700. In addition, mean refractive shift (MRS), mean absolute error (MAE) of PPR, and RIP as acquired in the IOL Master 700 and the VERION, were compared before and after IOL constant optimization for the VERION. Finally, the potential correlations between K-value in the IOL Master 700 and the VERION, both before and after IOL constant optimization and other variables were assessed.

\section{Methods}

\section{Study population}

This retrospective study included 72 eyes from 42 patients with cataracts, who underwent uneventful phacoemulsification with IOL implantation (SN60WF, Alcon Laboratories, Inc., Fort Worth, TX, USA), at Yokohama Tsurumi Chuoh Eye Clinic or Yokosuka Chuoh Eye Clinic in Japan. Additional inclusion criteria included, patients with good quality IOL Master 700 and VERION Reference Unit measurements, as indicated by both devices and post-operative best-corrected visual acuities better than 20/40. Patients with an anterior segment eye problem, high corneal irregular astigmatism, a history of traumatic or uveitis cataracts, intraocular or corneal operation, or intra- or post-operative complications were excluded. The average age was 73.8 years \pm 7.7 SD (range: $50-86$ years), and $40.48 \%$ of patients were men (Table 1 ).

Table 1 Basic information of participants included for analysis 


\begin{tabular}{|llll|}
\hline & Mean & Range & p value $^{1}$ \\
\cline { 1 - 3 } Age (years) & 73.8 & $50-86$ & NA $^{2}$ \\
\cline { 1 - 3 } Gender & & & \\
\cline { 1 - 3 } Men $(\%)$ & $17(40.48 \%)$ & NA & $0.2170^{3}$ \\
\cline { 1 - 3 } Women $\mathrm{n}(\%)$ & $25(59.52 \%)$ & NA & \\
\hline
\end{tabular}

1. $p$ value defined as statistically significant at $p<0.05$ level

2. Not Applicable

3. Chi-square test for categorical variables

All research and data collection methods were conducted in line with the tenets of the Declaration of Helsinki. This study was approved by the ethical committees of both institutes (Yokohama Tsurumi Chuoh Eye Clinic and Yokosuka Chuoh Eye Clinic), and conducted between January and April 2018. Patients gave consent to review their medical records for this study.

\section{Optic biometers}

The VERION Reference Unit measures keratometry parameters and captures anterior segment imagebased biometric identification. The system uses three infrared projections on the anterior corneal surface. The combination of 12 corneal-reflected light spots from monochromatic light emitting diode (LED) sources mainly measures $\mathrm{K}$-value at a range of 0.8 to $1.2 \mathrm{~mm}$ from the corneal apex. It also checks at 2.8 $\mathrm{mm}$ from the apex to adjust the measurement data.

IOL Mater 700 uses new swept source optical coherent tomography. This device has an ability to measure K-value, anterior chamber depth (ACD), lens thickness, and axial length (AL). K-value is measured at $2.5 \mathrm{~mm}$ from the corneal apex.

K-value was obtained using an IOL Master 700 and VERION. Since we used SRK/T to calculate PPR and RIP using an IOL Master and VERION, AL was required. However, apart from K-value, the VERION does not have an ability to measure AL. Thus, AL measured by the IOL Master 700 was applied to the calculation of PPR and RIP. In addition, while an optimized IOL constant for the IOL Master 700, is provided by the User Group for Laser Interference Biometry (ULIB), it is not for the VERION. Therefore, the optimized IOL constant for the IOL Master was also applied to the VERION.

The VERION requires a minimum of 30 cases to optimize the IOL constant. In this study, refractive data from three months of post-operative checks in 112 cases were used to optimize the IOL constant for the VERION. After optimization, the optimized IOL constant for the VERION (VERION new A) was used to calculate the PPR and RIP in it. 
Through the processes above, PPR and RIP using the IOL Master 700 and the VERION, both before and after IOL constant optimization for the VERION were obtained.

K-value, MRS of PPR, MRE of PPR and RIP were compared between the IOL Master 700 and the VERION, before and after IOL constant optimization for VERION MRS, MRE and RIP were compared between the preoperative and post-operative refractive data obtained from post-operative checks, and 3 months after the operation. The correlations between K-value and other biometric variables were analyzed, both before and after IOL optimization for the VERION.

\section{Statistical analysis}

We assessed the normality of distribution of each continuous variable, K-value and PPR using the Kolmogorov-Smirnov test; all showed a non-parametric distribution. To compare the K-value, MRS of PPR, MRE of PPR, and RIP between the IOL Master 700 and the VERION before and after IOL constant optimization for the VERION, the Wilcoxon signed-rank test was used. To investigate the correlation of the variables, the Spearman's rank-order correlation test was used. A value of $p<0.05$ was considered statistically significant in this research (two-sided $p$ value). The Bell Curve for Excel, version 1.03 (Social Survey Research Information Co, Ltd., Tokyo, Japan) was used to analyze statistical data.

\section{Results}

Mean K-values in the VERION (44.902 $\pm 1.482 \mathrm{D})$ were significantly higher than in the IOL Master 700 $(44.530 \pm 1.525 \mathrm{D})(\mathrm{p}<0.0001)($ Table 2$)$.

Table 2 Comparison of K-Value between VERION and IOL Master

\begin{tabular}{|llllll|}
\hline & & & \multicolumn{3}{c|}{$($ K VERION $)-($ K IOL Master $)$} \\
\hline Device & Mean K-value $( \pm$ SD $)$ & p value & $n<0$ & $n=0$ & $n>0$ \\
\hline VERION & $44.902( \pm 1.482)$ & 0.0001 & 16 & 0 & 56 \\
\hline IOL Master & $44.530( \pm 1.525)$ & & & & \\
\hline
\end{tabular}

Table 3 shows MRS of PPR in the IOL Master 700 and VERION, before and after IOL constant optimization for VERION. Before IOL constant optimization, MRS of PPR in the VERION $(-0.726 \pm 0.252)$ showed a significantly more myopic shift, compared to the IOL Master $700(0.143 \pm 0.369)(p<0.0001)$. However, after IOL constant optimization, the difference in MRS of PPR $(-0.009 \pm 0.031)$, disappeared $(p=$ 0.1180). 
Table 3 Comparison of mean refractive shift of predicted post-operative refraction between VERION and IOL Master

\begin{tabular}{|c|c|c|c|c|c|c|c|c|}
\hline Device & $\mathrm{IOL}$ & VERION & & VERION & & \multicolumn{3}{|c|}{ Difference } \\
\hline Mean $( \pm S D)$ of RS & $\begin{array}{l}0.143( \pm \\
0.369)\end{array}$ & $\begin{array}{l}-0.726( \pm \\
0.252)\end{array}$ & $<.0001$ & $\begin{array}{l}-0.009 \\
0.031)\end{array}$ & 0.1180 & $\begin{array}{l}\mathrm{n} \\
< \\
0\end{array}$ & $\begin{array}{l}\mathrm{n} \\
= \\
0\end{array}$ & $\begin{array}{l}n \\
> \\
0\end{array}$ \\
\hline $\begin{array}{l}\text { (RS VERION) - (RS IOL } \\
\text { Master) }\end{array}$ & $N A^{4}$ & $N A^{4}$ & $N A^{4}$ & $N A^{4}$ & $N A^{4}$ & 72 & 0 & 0 \\
\hline $\begin{array}{l}\text { (RS VERION) - (RS } \\
\text { VERION new A) }\end{array}$ & $N A^{4}$ & $N A^{4}$ & $\mathrm{NA}^{4}$ & $\mathrm{NA}^{4}$ & $N A^{4}$ & 0 & 0 & 72 \\
\hline $\begin{array}{l}\text { (RS VERION new A) - } \\
\text { (RS IOL Master) }\end{array}$ & $N A^{4}$ & $N A^{4}$ & $N A^{4}$ & $N A^{4}$ & $N A^{4}$ & 51 & 0 & 21 \\
\hline
\end{tabular}

1) IOL Master compared to VERION

2) VERION after IOL-constant optimization

3) IOL Master compared to VERION new A

4) Not applicable.

Table 4 demonstrates MAE of PPR in the IOL Master 700 and VERION before and after IOL constant optimization. Before IOL constant optimization for the VERION, MAE of PPR $(0.726 \pm 0.252)$ was significantly higher than in the IOL Master $700(0.331 \pm 0.213)(p<0.0001)$. Although, after IOL constant optimization for VERION, MAE of PPR in it $(0.147 \pm 0.095)$ became significantly lower than in the IOL Master $700(0.331 \pm 0.213)(p<0.0001)$.

Table 4 Comparison of absolute error of predicted post-operative refraction between VERION and IOL Master 


\begin{tabular}{|c|c|c|c|c|c|c|c|c|}
\hline \multirow{2}{*}{$\begin{array}{l}\text { Device } \\
\text { Mean }( \pm S D) \text { of } A E\end{array}$} & \multirow{2}{*}{$\begin{array}{l}\text { IOL } \\
\text { Master } \\
0.331( \pm \\
0.213)\end{array}$} & \multirow{2}{*}{$\begin{array}{l}\text { VERION } \\
0.726 \text { ( } \pm \\
0.252)\end{array}$} & \multirow{2}{*}{$\begin{array}{l}p \\
\text { value }^{1} \\
< \\
0.0001\end{array}$} & \multirow{2}{*}{$\begin{array}{l}\text { VERION } \\
\text { new } A^{2} \\
0.147( \pm \\
0.095)\end{array}$} & \multirow{2}{*}{$\begin{array}{l}\mathrm{p} \\
\text { value }^{3} \\
< \\
0.0001\end{array}$} & \multicolumn{3}{|c|}{ Difference } \\
\hline & & & & & & $\begin{array}{l}\mathrm{n} \\
< \\
0\end{array}$ & $\begin{array}{l}\mathrm{n} \\
= \\
0\end{array}$ & $\begin{array}{l}\mathrm{n} \\
> \\
0\end{array}$ \\
\hline $\begin{array}{l}\text { (AE VERION) - (AE IOL } \\
\text { Master) }\end{array}$ & $N A^{4}$ & $\mathrm{NA}^{4}$ & $N A^{4}$ & $\mathrm{NA}^{4}$ & $\mathrm{NA}^{4}$ & 11 & 0 & 61 \\
\hline $\begin{array}{l}\text { (AE VERION) - (AE } \\
\text { VERION new A) }\end{array}$ & $N A^{4}$ & $\mathrm{NA}^{4}$ & $\mathrm{NA}^{4}$ & $\mathrm{NA}^{4}$ & $\mathrm{NA}^{4}$ & 72 & 0 & 0 \\
\hline $\begin{array}{l}\text { (AE VERION new A) - (AE } \\
\text { IOL Master) }\end{array}$ & $N A^{4}$ & $N A^{4}$ & $N A^{4}$ & $N A^{4}$ & $\mathrm{NA}^{4}$ & 53 & 3 & 16 \\
\hline
\end{tabular}

1) IOL Master compared to VERION

2) VERION after IOL-constant optimization

3) IOL Master compared to VERION new A

4) Not Applicable

Table 5 illustrates the mean of RIP, calculated using the IOL Master 700 and VERION, before and after IOL constant optimization. The same table also shows the difference in RIP, in both devices, both before and after IOL constant optimization. Prior to IOL constant optimization for VERION, the mean RIP (20.556 \pm $2.640)$ was significantly lower than in the IOL master $700(21.701 \pm 2.690)(p<0.0001)$. However, after IOL constant optimization for the VERION, its mean RIP $(21.486 \pm 2.772)$ significantly increased, and it got much closer to the one in the IOL Master $700(21.701 \pm 2.690)$. Thus, the statistical significance disappeared $(p=0.0946)$.

Table 5 Comparison of recommended IOL power between VERION and IOL Master 


\begin{tabular}{|c|c|c|c|c|c|c|c|c|}
\hline Device & $\mathrm{IOL}$ & VERION & & VERION & & \multicolumn{3}{|c|}{ Difference } \\
\hline Mean $( \pm S D)$ of RIP & $\begin{array}{l}21.701( \pm \\
2.690)\end{array}$ & $\begin{array}{l}20.556( \pm \\
2.640)\end{array}$ & $\dot{0} 001$ & $\begin{array}{l}21.486( \pm \\
2.772)\end{array}$ & 0.0946 & $\begin{array}{l}\mathrm{n} \\
< \\
0\end{array}$ & $\begin{array}{l}\mathrm{n} \\
= \\
0\end{array}$ & $\begin{array}{l}\mathrm{n} \\
> \\
0\end{array}$ \\
\hline $\begin{array}{l}\text { (RIP VERION) - (RIP IOL } \\
\text { Master) }\end{array}$ & $N A^{4}$ & $N A^{4}$ & $N A^{4}$ & $N A^{4}$ & $N A^{4}$ & 68 & 4 & 0 \\
\hline $\begin{array}{l}\text { (RIP VERION) - (RIP } \\
\text { VERION new A) }\end{array}$ & $\mathrm{NA}^{4}$ & $\mathrm{NA}^{4}$ & $N A^{4}$ & $N A^{4}$ & $N A^{4}$ & 0 & 0 & 72 \\
\hline $\begin{array}{l}\text { (RIP VERION new A) - } \\
\text { (RIP IOL Master) }\end{array}$ & $N A^{4}$ & $N A^{4}$ & $N A^{4}$ & $N A^{4}$ & $\mathrm{NA}^{4}$ & 37 & 20 & 15 \\
\hline
\end{tabular}

1) IOL Master compared to VERION

2) VERION after IOL-constant optimization

3) IOL Master compared to VERION new A

4) Not Applicable

Table 6 and Fig. 1, show the correlation between K-value and the other variables in the IOL Master 700 and VERION before and after IOL constant optimization. The correlation between K-value and MRS of PPR in the IOL Master 700 was the only significantly negative correlation found (Spearman's rho $=-0.34$, $p<0.005)$. In the IOL Master 700, there was no significant correlation between K-value and MAE of PPR and RIP. Concerning the VERION, there was no significant correlation between K-value and the other variables, before and after IOL constant optimization.

Table 6 Correlation of K-value with other parameters 


\begin{tabular}{|llll|}
\hline \multirow{2}{*}{ Parameter } & & \multicolumn{2}{l}{ Correlation with K-value } \\
\cline { 2 - 4 } RS & Device & Rho & $\mathrm{p}$ \\
\cline { 2 - 4 } & IOL Master & -0.34 & $\mathbf{0 . 0 0 3 3}$ \\
\cline { 2 - 4 } & VERION & -0.22 & 0.057 \\
\cline { 2 - 4 } & VERION new A & -0.21 & 0.072 \\
& IOL Master & 0.11 & 0.38 \\
\cline { 2 - 4 } & VERION & 0.22 & 0.057 \\
\cline { 2 - 4 } & VERION new A & 0.052 & 0.66 \\
& IOL Master & 0.06 & 0.62 \\
\cline { 2 - 4 } & VERION & 0.18 & 0.12 \\
\cline { 2 - 4 } & VERION new A & 0.21 & 0.07 \\
\cline { 2 - 4 } & & &
\end{tabular}

\section{Discussion}

This is the first research, which showed the importance of IOL constant optimization for the VERION to improve the accuracy of its post-operative refractive prediction. K-value in the IOL Master 700 was significantly different from the one acquired from the VERION. Regarding predicted post-operative refraction, before IOL constant optimization, the VERION showed a significant myopic shift compared to the IOL Master 700. Additionally, the VERION was significantly less accurate in PPR than the IOL Master 700. Furthermore, RIP in the VERION was significantly lower than the IOL Master 700. However, after IOL constant optimization, the performance of the VERION dramatically improved and the myopic shift of PPR became insignificant compared to the IOL Master 700. Interestingly enough, the VERION became significantly more accurate than the IOL Master 700. Furthermore, RIP in the VERION came close to that of the IOL Master 700. Concerning the correlation between $\mathrm{K}$-value and other variables, $\mathrm{K}$-value and refractive shift (RS) of post-operative refraction was the only significant correlation found.

$\mathrm{K}$-value is one of the most important variables for the IOL calculation formulas [7-9]. Edmund et al. showed that the radius of corneal curvature changed between $1 \mathrm{~mm}$ and $5 \mathrm{~mm}$ from the corneal apex and the more central the cornea, the steeper it is [11]. Various optic biometers are currently available to measure K-value, and each device takes measurements at a different part of the cornea. For instance, the VERION, Lenstar (Haag-Streit, Switzerland) and IOL master measure corneal curvature at 0.8-1.2 mm, 1.6 $\mathrm{mm}$ and $2.3 \mathrm{~mm}$, and $2.5 \mathrm{~mm}$ from the apex of cornea, respectively. Holladay illustrated the example of the theoretical differences in K-value among these devices [13]. When K-value in the VERION is $44.7 \mathrm{D}$, theoretically speaking, the same values in the Lenstar and IOL master should be $44.5 \mathrm{D}$ and $44.3 \mathrm{D}$ respectively. In this study, the mean K-value in VERION was $0.36 \mathrm{D}$, higher than the one in the IOL master and the difference was significant. This result comes in agreement with the aforementioned report [13]. 
The VERION image-guided system is a surgical-assisted system, used both pre- and intraoperatively. The image taken pre-operatively can be applied for auto-registration using the intra-operative digital marker. This system is useful to insert a toric IOL and create limbal relaxing incisions (LRI) in place [14]. The VERION Reference Unit is the biometer to measure K-value and capture the image of the anterior segment pre-operatively. The image is integrated with the VERION image-guided system to be used for intraoperative registration and provides real-time visual image marking through a microscope. The imageguided system is also combined with the femtosecond laser cataract surgery platform. The Reference Unit functions for corneal incision design and LRI [14]. This subsequent process has the potential to improve the refractive outcome. Although this state-of-the-art system sounds very sophisticated, there are also some concerns about this process. The VERION Reference Unit measures K-value at a different distance from the corneal apex compared to other major biometers. Additionally, it currently cannot measure essential biometric variables, such as ACD and AL to calculate post-operative refraction and RIP. Therefore, the VERION needs to use ACD and AL measured by different optic biometers. Furthermore, although the IOL constant is also a crucial factor for IOL calculation formulas, a published optimized IOL constant for the VERION, such as the one provided by the ULIB, does not currently exist. Since the IOL Master 700 and Lenstar are currently the gold standard optical biometers [20, 21], most research on the importance of IOL constant optimization is conducted with the IOL Master or Lenstar. Hsieh et. al. demonstrated that optimization of IOL constants for the IOL Master, significantly improved the accuracy of IOL calculation [22]. Aristodemou et al. [23], also reported that the IOL constant optimization could significantly improve the refractive outcome [23]. While they supported the importance of personalization of the IOL constant, Charalampidou [24] mentioned that the published IOL constant from the ULIB is as accurate as the personalized IOL constant, unless surgeons perform an extremely high number of operations per year and only use specific models for a relatively long time to apply the data for the optimization [24]. The result indicated that although personalization of IOL constant is still ideal, for the majority of surgeons, the published IOL constant from the ULIB is very useful. However, as of now, the optimized IOL constant for the VERION has not been provided by the ULIB [25]. Therefore, IOL manufacturers advise the first user of the VERION to apply the published IOL constant provided by the ULIB.

Again, K-value is one of the most important factors for the calculation of post-operative refraction and RIP, but K-value is measured at different areas from the apex of the cornea, when using a VERION or IOL Master. Therefore, to utilize the best of the functions of the VERION, it is worth investigating how the application of the published IOL constant affects the tendency and accuracy of PPR and RIP calculated using the VERION, and how the IOL optimization for it, improves outcomes.

In this study, we compared K-value, MRS of PPR, MAE of PPR, and RIP between the IOL Master 700 and the VERION, before and after IOL constant optimization. The correlations between K-value and all variables, were also analyzed. K-value in the VERION was significantly higher than in the IOL Master. This result was in line with past research $[12,13]$. Prior to optimization, the VERION showed a significantly more myopic shift in MRS of PPR, higher MAE of PPR, and lower RIP than the IOL Master 700. These results indicate that before IOL constant optimization for the VERION, the device is significantly less 
accurate than the IOL Master 700, and the shift of PPR and RIP, has a particular tendency. However, after IOL-constant optimization for the VERION, the myopic refractive shift of PPR disappeared. MRE of PPR significantly improved, and interestingly enough, MRE of PPR in the VERION was significantly lower than the IOL Master 700. Additionally, concerning the RIP, it significantly increased in the VERION and came close to that of the IOL Master. These results indicate that after IOL optimization for the VERION, it turns out to be significantly more accurate than the IOL Mater 700. This finding has increased clinical significance as it can result in an improved quality of life and more independence from spectacles [26] for a patient who has undergone cataract surgery. The aforementioned particular tendencies disappeared. Regarding the correlation of K-value with RS of PPR, absolute error of PPR, and RIP in the VERION, Kvalue showed no influence on these three variables, regardless of IOL constant optimization. Whereas, Kvalue significantly affected RS of PPR, where the higher K-value the more myopic shift the PPR showed. This result comes in agreement to previous research [27]. Thus, we do not need to take the influence of Kvalue on PPR and RIP into consideration when we use the VERION, but we do need to take the influence of K-value on only PPR when we use the IOL Master.

A potential limitation of the current study is that a vital variable (AL) needed for the calculation of PPR and RIP, was not provided from the VERION and thus, the ones obtained from the IOL Master 700 were employed. Although, this was expected to have biased our results in favor of the IOL Master 700, that was not the case. It would be useful to have a published IOL constant for the VERION to assess in the future whether the pattern of the aforementioned results will change. Moreover, it can be inferred that the VERION has been found to have an accuracy close to that of gold standard devices, such as the IOL Master 700. Finally, future research could focus on the quality of vision and quality of life of those in whom post-operative outcome measurements are taken with the VERION.

\section{Conclusion}

The VERION was less reliable than the IOL Master 700 before IOL constant optimization. That being said IOL constant optimization significantly improved its predictability. Moreover, after IOL constant optimization, the VERION became significantly more accurate than IOL Master 700.

The results of this research indicate the importance of IOL constant optimization for the VERION to improve post-operative refraction, and to make the most of the strengths of both the VERION imageguidance system and its Reference Unit. Finally, the release of a published IOL constant for the VERION from ULIB is also expected.

\section{Declarations}

\section{Ethical Approval/Informed Consent}

The study was approved by ethical committees at Yokosuka Chuoh and Tsurumi Chuoh Eye clinics. Written informed consent for publication of their clinical details and/or clinical images was obtained 
from all patients. A copy of the consent form is available for review by the Editor of this journal.

\section{Availability of data and materials}

The data used and analyzed for the current study are available upon reasonable request from the corresponding author

\section{Competing interests}

None of the researchers involved in this study have any affiliations with, or involvement, in any organization or entity with any financial or non-financial interest.

\section{Funding}

This research was unfunded

\section{Authors Contributions}

T.T: Conception, T.T., A.M., and N.M: design, T.T: data collection, A.M: data analysis, T.T., AM., and N.M: data interpretation, T.T: draft article, T.T. and N.M: article revision, T.T., M.A. and N.M: final approval

\section{Acknowledgements}

This study was presented in September 2019 at the Meeting of European Society of Cataract and Refractive Surgeons, Paris Expo Porte de Versailles, Paris, France. We would like to thank Editage (www.editage.com) for English language editing. Editorial support, in the form of medical writing, assembling tables and creating high-resolution images based on authors' detailed directions, collating author comments, copyediting, fact checking, and referencing, was provided by Editage and Cactus Communications

\section{Author Information}

Dr. T.T: Yokosuka Chuoh Eye Clinic, Yokosuka, Kanagawa, Japan

Dr. A.M: Department of Ophthalmology, Yokohama City University School of Medicine, akmeguro@yokohama-cu.ac.jp

Prof. N.M: Department of Ophthalmology, Yokohama City University School of Medicine, Yokohama, Kanagawa, Japan, mizunobu@yokohama-cu.ac.jp

Corresponding author: Dr. Takeshi Teshigawara

Affiliation: Yokosuka Chuoh Eye Clinic

Address: 238-0008, 2-6 Odaki-cho, Yokosuka, Kanagawa, Japan 
Tel: +81468274001

Fax: +81468274141

E-mail: teshitake@gmail.com

\section{Abbreviations}

$\mathrm{ACD}=$ Anterior Chamber Depth

$A L=$ Axial Length

$\mathrm{IOL}=$ Intra-ocular Lens

LRI = Limbal Relaxing Incisions

$\mathrm{MAE}=$ Mean Absolute Error

MRS $=$ Mean Refractive Shift

PPR $=$ Predicted Post-operative Refraction

RIP = Recommended IOL Power

RS = Refractive Shift

ULIB = User group for Laser Interference Biometry

\section{References}

1. Lee AC, Qazi MA, Pepose JS. Biometry and intraocular lens power calculation. Curr Opin Ophthalmol. 2008;19:13-7.

2. Kielhorn I, Rajan MS, Tesha PM, Subryan VR, Bell JA. Clinical assessment of the Zeiss IOLMaster. J Cataract Refract Surg. 2003;29:518-22.

3. Németh J, Fekete O, Pesztenlehrer N. Optical and ultrasound measurement of axial length and anterior chamber depth for intraocular lens power calculation. J Cataract Refract Surg. 2003;29:858.

4. Alio J, Plaza-Puche AB, Férnandez-Buenaga R, Pikkel J, Maldonado M. Multifocal Intraocular Lenses: An Overview. Surv Ophthalmol. 2017;62:611-34.

5. Hui S, Yi L. Comparison of two optical biometers in intraocular lens power calculation. Indian J Ophthalmol. 2014;62:931-4.

6. Lee AC, Qazi MA, Pepose JS. Biometry and intraocular lens power calculation. Curr Opin Ophthalmol. 2008;19:13-7. 
7. Barrett GD. An improved universal theoretical formula for intraocular lens power prediction. $J$ Cataract Refract Surg. 1993;19:713-20.

8. Retzlaff JA, Sanders DR, Kraff MC. Development of the SRK/T intraocular lens implant power calculation formula. J Cataract Refract Surg. 1990;16:333-40.

9. Hoffer KJ. Clinical results using the Holladay 2 intraocular lens power formula. J Cataract Refract Surg. 2000;26:1233-7.

10. Ferrer-Blasco T, Montés-Micó R, Peixoto-de-Matos SC, González-Méijome JM, Cerviño A. Prevalence of corneal astigmatism before cataract surgery. J Cataract Refract Surg. 2009;35:70-5.

11. Edmund C, Sjøntoft E. The central-peripheral radius of the normal corneal curvature. A photokeratoscopic study. Acta Ophthalmol (Copenh). 1985;63:670-7.

12. Scott A. Read, Michael J. Collins, Leo G. Carney, The Topography of the Central and Peripheral Cornea. Invest Ophthalmol Vis Sci. 2006;47:1404-15

13. Holladay JT -Ocular Surgery News US Edition October 10, 2014

14. Reggiani-Mello G, Krueger RR. Comparison of commercially available femtosecond lasers in refractive surgery. Expert Rev Ophthalmol. 2011;6:55-65

15. Schultz $\mathrm{M}$, Oberheide $U$, Kermani $\mathrm{O}$. Comparability of an image-guided system with other instruments in measuring corneal keratometry and astigmatism. J Cataract Refract Surg. 2016 Jun;42:904-12.

16. Lin HY, Chen HY, Fam HB. Comparison of corneal power obtained from VERION image-guided surgery system and four other devices. Clin Ophthalmol. 2017; 12:1291-9.

17. Lin H-Y, Chen H-Y, Fam HB, Chuang Y-J, Yeoh R, Lin P-J. Comparison of corneal power obtained from VERION image-guided surgery system and four other devices. Clin Ophthalmol. 2017;11:1291-9.

18. Nemeth G, Szalai E, Hassan Z, Lipecz A, Berta A, Modis L. Repeatability Data and Agreement of Keratometry With the VERION System Compared to the IOLMaster. J Refract Surg. 2015;31:333-7.

19. Hura AS, Osher RH. Comparing the Zeiss Callisto Eye and the Alcon Verion Image Guided System Toric Lens Alignment Technologies. J Refract Surg. 2017;33:482-7.

20. Kongsap P. Comparison of a new optical biometer and a standard biometer in cataract patients. Eye Vis (Lond). 2016;3:27.

21. Srivannaboon S, Chirapapaisan C, Chonpimai P. Clinical comparison of a new swept-source optical coherence tomography-based optical biometer and a time-domain optical coherence tomographybased optical biometer. J Cataract Refract Surg. 2015;41:2224-32.

22. Hsieh YT, Wang IJ. Intraocular lens power measured by partial coherence interferometry. Optom Vis Sci. 2012;89:1697-701.

23. Aristodemou P, Knox Cartwright NE, Sparrow JM. Intraocular lens formula constant optimization and partial coherence interferometry biometry: Refractive outcomes in 8108 eyes after cataract surgery. $J$ Cataract Refract Surg. 2011;37:50-62.

24. Charalampidou S. Effect on refractive outcomes after cataract surgery of intraocular lens constant. J Cataract Refract Surg. 2010;36:1081-9. 
25. User Group for Laser Interference Biometry. http://ocusoft.de/ulib/ (2016). Accessed 5 Jan 2018

26. Young C, Youngsub E, Jong S. Influence of corneal power on intraocular lens power of the second eye in the SRK/T formula in bilateral cataract surgery. BMC Ophthalmol. 2017;17:261.

27. Alio J, Plaza-Puche AB, Férnandez-Buenaga R, Pikkel J, Maldonado M. Multifocal Intraocular Lenses: An Overview. Surv Ophthalmol. 2017;62:611-34.

\section{Figures}


a

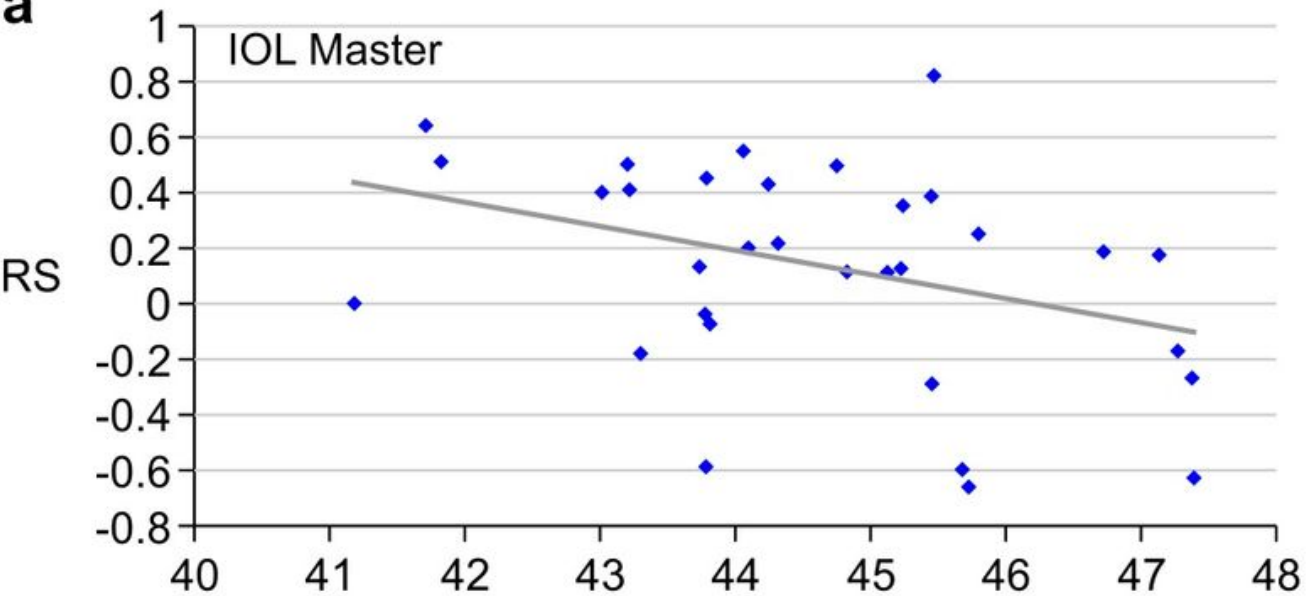

b
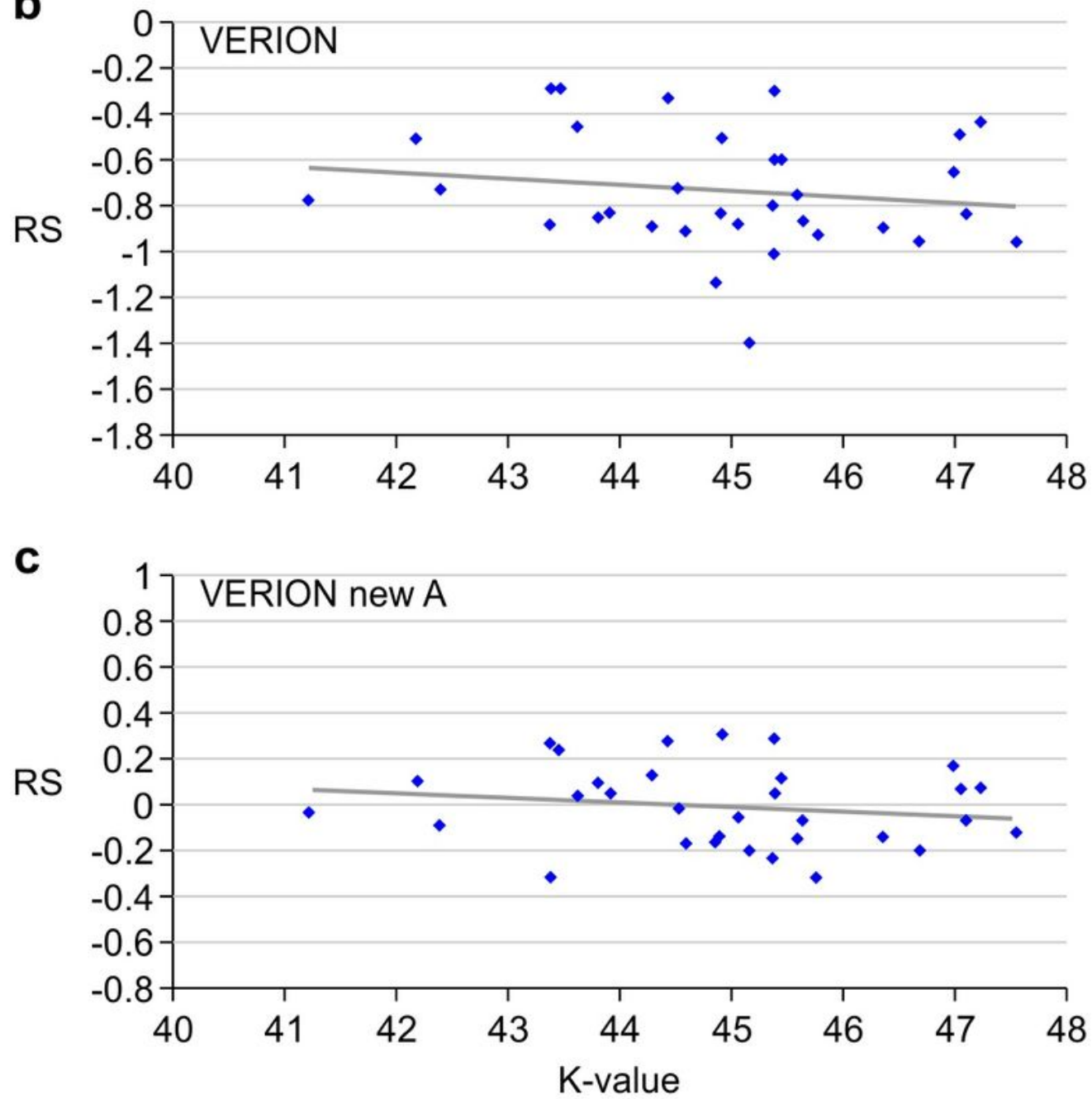

Figure 1

Correlation between refractive shift and K-Value in A: IOL Master 700, B: VERION, and C: VERION new A. (Abbreviations RS: refractive shift, AE: absolute error and RIP: recommended IOL power.) 